Article

\title{
Dielectric Insulation Characteristics of Natural Ester Fluid Modified by Colloidal Iron Oxide Ions and Silica Nanoparticles
}

\author{
Vasilios P. Charalampakos ${ }^{1}$, Georgios D. Peppas ${ }^{2, *}$, Eleftheria C. Pyrgioti ${ }^{2}$, \\ Aristides Bakandritsos ${ }^{3}$, Aikaterini D. Polykrati ${ }^{4}$ and Ioannis F. Gonos ${ }^{4}$ \\ 1 Department of Electrical and Computer Engineering, University of the Peloponnese, 26334 Patras, Greece \\ 2 Department of Electrical and Computer Engineering, University of Patras, 26500 Patras, Greece \\ 3 Regional Centre for Advanced Technologies and Materials, Department of Physical Chemistry, Faculty of \\ Science, Palacký University Olomouc, 17. listopadu 1192/12, 77146 Olomouc, Czech Republic \\ 4 School of Electrical and Computer Engineering, National Technical University of Athens, \\ 15780 Athens, Greece \\ * Correspondence: peppas@ece.upatras.gr
}

Received: 29 June 2019; Accepted: 17 August 2019; Published: 23 August 2019

check for updates

\begin{abstract}
In this study, the dielectric characteristics of two types of natural esters modified into nanofluids are studied. The AC breakdown voltage was investigated for colloidal $\mathrm{Fe}_{2} \mathrm{O}_{3}$ and $\mathrm{SiO}_{2}$ nanoparticles effectively scattered in natural ester oil. The experimental results identify an increase in the breakdown voltage of the nanofluid with colloidal $\mathrm{Fe}_{2} \mathrm{O}_{3}$ conductive nanoparticles. In contrast, the breakdown voltage was reduced by adding $\mathrm{SiO}_{2}$ nanoparticles in the same matrix. The potential well distribution of the two different types of nanoparticles was also calculated in order for the results of the experiment to be explained. The dielectric losses of the colloidal nanofluid are compared with the matrix oil and studied at $25^{\circ} \mathrm{C}$ and $100^{\circ} \mathrm{C}$ in the frequency regime of $10^{-1}-10^{6} \mathrm{~Hz}$. The experimental data and the theoretical study reveal that conductivity along with the permittivity of nanoparticles constitute a pivotal parameter in the performance of nanofluid. Specific concentrations of nanoparticles with different electrical conductivity and permittivity than those of matrix oil increase the breakdown voltage strength. Simultaneously, the addition of nanoparticles having electrical conductivity and permittivity comparable to the matrix oil results in reducing the breakdown voltage.

Keywords: nanofluids; nanoparticles; breakdown strength; transformer oils; permittivity; conductivity
\end{abstract}

\section{Introduction}

Insulating nanofluids have attracted the attention of researchers for the last twenty years. The dispersion of nanoparticles inside insulating oils can conditionally increase the breakdown voltage and thermal conductivity of matrix oil. Insulating fluids used in transformers exhibit high dielectric strength but their thermal conductivity is low and this introduces limitations on the power rating of the transformers, and, as a consequence, an increase in their size. Thus, the motivation for the insertion of nanoparticles within transformer oil was initially the increase of thermal conductivity. The idea of adding particles in order to increase thermal conductivity goes back to Maxwell in 1873 [1] and Choi et al. [2] were the first to add magnetic nanoparticles $\mathrm{Fe}_{3} \mathrm{O}_{4}$ to pure transformer oil and to develop the first nanofluid that demonstrated better thermal conductivity. However, several researchers soon realized that the dispersion of some nanoparticles increased the breakdown voltage at the same time [3-17] and their interest also turned to this direction. 
Researchers in [3-10] studied iron oxide nanoparticles, $\mathrm{Fe}_{3} \mathrm{O}_{4}$ and $\mathrm{Fe}_{2} \mathrm{O}_{3}$, and found they enhanced dielectric and the cooling performance of the constitutive base fluids when they were dispersed in either mineral or natural ester oils. The dispersion of two-dimensional nanoparticles, such as boron nitride (BN) or graphene nanoparticles, also enhanced the cooling capacities of transformer oil $[3,11]$. After these promising results, different nanofluids were developed using nanoparticles such as $\mathrm{TiO}_{2}$, $\mathrm{SiO}_{2}$, nanodiamond-Ni nanoparticles, and boron nitride (BN) $[7,11-19]$ and they were tested regarding their dielectric performance.

Semi-conductive $\mathrm{TiO}_{2}$ nanoparticles were added to natural ester oil and mineral oil matrix $[13,14]$ resulting in nanofluids with increased AC breakdown voltage (BDV) and lightning impulse withstand capability as compared to that of the matrix oils. In [15-17] high concentrations of $\mathrm{SiO}_{2}$ nanoparticles in mineral oil resulted in increased AC breakdown voltage and positive lightning impulse withstand capability in comparison with the matrix dielectric liquid. On the other hand, the negative lightning impulse voltage withstand capability was decreased. In addition, they highlighted the strong influence of moisture on the performance of nanofluids. Particularly, the higher the presence of humidity in the aforementioned $\mathrm{SiO}_{2}$ nanofluid the better its performance was. However, thermal conductivity seemed to be only slightly affected by the addition of $\mathrm{SiO}_{2}$ nanoparticles.

Aluminum nitride (AIN), graphene oxide, and BN nanoparticles, as dispersants in mineral oil, were also studied $[6,11,17,18]$. The addition of AIN nanoparticles proved to increase positive lightning impulse voltage withstand capability and partial discharge ignition voltage, as well as the thermal conductivity of nanofluid as compared with pure oil, and simultaneously, AC breakdown voltage was decreased. Similar results were demonstrated with the addition of BN and graphene oxide nanoparticles where both the AC BDV and the thermal conductivity were improved as compared with the matrix oil. A satisfactory explanation for the higher AC BDV of insulating nanofluids with higher conductivity nanoparticles, with respect to the matrix oils, was given by the "electron traps" theory in [20]. According to this, electrons are very rapidly captured by conductive nanoparticles being transmuted into heavy negatively charged nanoparticles. As a consequence, the streamer speed was reduced resulting in an increased breakdown voltage. Experimental results concerning the space charge in both matrix oil and nanofluid oils [21] were in compliance with the proposed theory.

However, the aforementioned theory fails to adequately explain the superior performance of nanofluids with semi-conductive and non-conductive nanoparticles which have been observed with the conductive ones. This can be ascribed, according to a theory [22], to the different conductivity or permittivity between nanoparticles and their surrounding oil and, according to others $[12,23,24]$, to the interfacial region shaped on the surface of the nanoparticles (NPs).

In this study the AC BDV of two completely different natural ester oil matrix nanofluids will be examined. Conductive in situ surface modified colloidal magnetic iron oxides NPs (MIONs) and $\mathrm{SiO}_{2}$ nanoparticles were scattered into natural ester dielectric liquid (FR3 ${ }^{\circledR}$ ). Different nanoparticle concentrations were tested with respect to the optimal concentration in terms of AC dielectric strength performance. The theoretical model proposed in [22] was realized in order to interpolate the experimental results.

\section{Materials and Methods}

During the preparation of the nanofluids, natural ester dielectric liquid Envirotemp FR3 ${ }^{\circledR}$ was used as base liquid which was selected due to its biodegrability and high temperature flash point.

At first, the matrix oil was triple filtered and dried as analytically described in [10]. In brief, low vacuum filtration was used by applying a $30 \mu \mathrm{m}$ filter for the first level, a $1 \mu \mathrm{m}$ glass microfiber filter for the second level, and a $0.8 \mu \mathrm{m}$ membrane for the last one. Thereafter, the matrix liquid was dehumidified by means of a rotary evaporator in series with a vacuum pump, while it was positioned in a water bath heated at $80^{\circ} \mathrm{C}$ for at least two days.

The preparation of the nanofluids (NFs) with oleate-coated colloidal magnetic iron oxide nanocrystals (colMIONs) required particular care because magnetic iron oxide nanoparticles, such as 
$\mathrm{Fe}_{2} \mathrm{O}_{3}$ and $\mathrm{Fe}_{3} \mathrm{O}_{4}$, have a tendency to indicate residual NPs after their dispersion in the matrix liquid, forming sedimentation within a few days. In an attempt to overcome agglomeration and increase the long-term stability of the nanofluid, oleate-coated colloidal magnetic iron oxide nanocrystals (colMIONs) were manufactured in the laboratory according to previous reports [9,25]. Initially, $3.62 \mathrm{~g}$ of iron-oleate complex and $3.4 \mathrm{~g}$ of oleic acid were dissolved in 1-octadence at a temperature of $25{ }^{\circ} \mathrm{C}$. For $1 \mathrm{~h}$, the mixture was magnetically agitated at room temperature, then it was kept under agitation (350 rpm) for $30 \mathrm{~min}$ at a temperature of $100^{\circ} \mathrm{C}$ and, finally, it was further heated at $318^{\circ} \mathrm{C}$ for another hour [26]. Afterwards, the commixture was cooled down and $8 \mathrm{~mL}$ of dichloromethane was added. Subsequently, acetone as a dissolver was introduced to decrease the solubility of the MIONs, as well as separate the reacting agents from them. This manufacturing method was repeated until the oleate-coated MIONs obtained a purity level higher than $80 \%$. The colMIONs had a final diameter of approximately $10 \mathrm{~nm}$ with a very narrow dimensional distribution [9], and thereafter, they were introduced into the natural ester oil and the final liquid was ultrasonicated for at least $30 \mathrm{~min}$. Six samples, having a concentration range from 0.004 to $0.014 \% w / w$, in step $0.002 \%$ were prepared for further study.

Nanoparticles $\mathrm{SiO}_{2}$ are well dispersed inside transformer oil and they do not indicate agglomeration effect. On the contrary, they may absorb humidity during the introduction of atmospheric air within 3-4 s. Therefore, the procedure took place in a shielded AtmosBag with dedicated gloves (Aldrich ${ }^{\circledR}$ AtmosBag) while inside $\mathrm{N}_{2}$ was introduced. After the addition of $12 \mathrm{~nm}$ average diameter $\mathrm{SiO}_{2}$ nanoparticles to the matrix oil, the final liquid was ultrasonicated for $30 \mathrm{~min}$. Six different samples with concentrations ranging from $0.008-0.024 \% w / w$ in step $0.004 \%$ were also prepared.

The measurements of AC dielectric breakdown strength carried out for the samples of the two nanofluids according to IEC 60156 in [27] were enriched with additional ones. The measurement device used was a Baur DTA 100 C, measuring up to $100 \mathrm{kV}$, Rogowski electrodes based on IEC 60156 [28] with a gap distance of $2.5 \mathrm{~mm}$, a voltage rise of $2 \mathrm{kV} / \mathrm{s}$ was adjusted at $50 \mathrm{~Hz}$ power system, the breakdown event is calculated based on the level of the current conduction ( $\mathrm{mA}$ range). The distribution of the breakdown voltage of the experimental results is calculated based on the normal distribution [10]. Before each experimental set, the brass electrodes were polished and cleaned thoroughly. For the matrix oil, 150 breakdown tests were implemented for every sample, whereas, after every 50 successful breakdowns the sample under test was replaced in order to limit the degradation and its effect on the measurements.

Dielectric relaxation spectroscopy was studied by means of a Novocontrol Alpha analyzer $\left(10^{-1}-10^{6} \mathrm{~Hz}\right)$ monitored from a Novocontrol Quatro Cryosystem. The understudied dielectric liquid was studied in a custom-made cylindrical capacitor which consisted of two plane plates at $1-1.2 \mathrm{~mm}$ distance. The dielectric relaxation spectroscopy study was adopted at $20-100^{\circ} \mathrm{C}$ with a $20^{\circ} \mathrm{C}$ temperature increase rate at the frequency range of $10^{-1}-10^{6} \mathrm{~Hz}$.

Dynamic light scattering (DLS) was performed on oil dispersions of $<0.01 \% w / v$ in $\mathrm{Fe}_{2} \mathrm{O}_{3}$ using the viscosity of the oil $32.03 \mathrm{~mm}^{2} / \mathrm{s}$. A Malvern Instrument ZetaSizer Nano was used, equipped with a $4 \mathrm{~mW}$ He-Ne laser, operating at a wavelength of $633 \mathrm{~nm}$. Scattered light was collected at a fixed angle of $173^{\circ}$. Diameter distribution was reported as number-based results. Transmission electron microscope images were collected with a JEOL 2100 on $200 \mathrm{kV}$. It should be noted that the DLS technique systematically provides a higher mean size of the crystallite size than the TEM technique, because in the former case the size is evaluated in the dispersion state and takes into account the organic coating of the magnetic crystallites, their solvation sphere, and possible formation of dyads between particles. In Figure 1 the size distribution of the colloidal MIONs in the oil matrix is depicted with a peak value of $23 \mathrm{~nm}$, accordingly, in the same figure the colloidal stability of the nanoparticles in the matrix oil after 2 months of storage is depicted. In Figure 2 a detailed TEM micrograph from the oleate-coated MIONs, as manufactured through the thermolytic route [9], is shown, clearly demonstrating their proper dispersion in absence of agglomeration. 


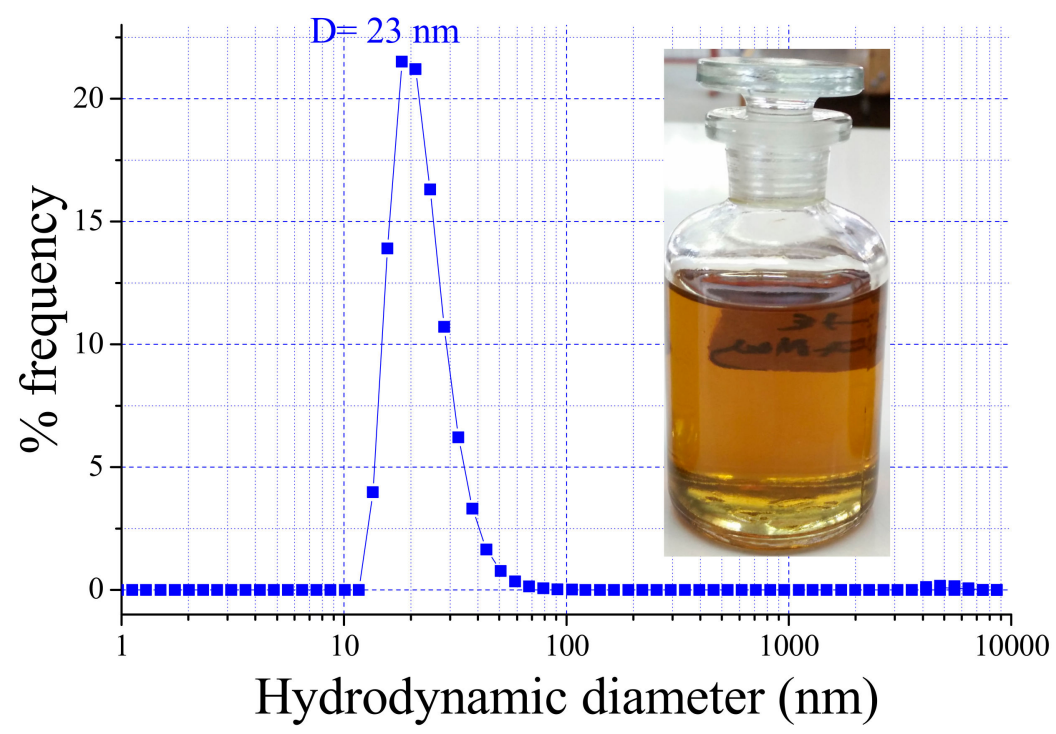

Figure 1. Size distribution diagram based on dynamic light scattering measurement of the colloidal magnetic iron oxides nanoparticles (MIONs) in the oil matrix and digital image colloidal nanofluid (colNF) after 2 months of storage (inset).

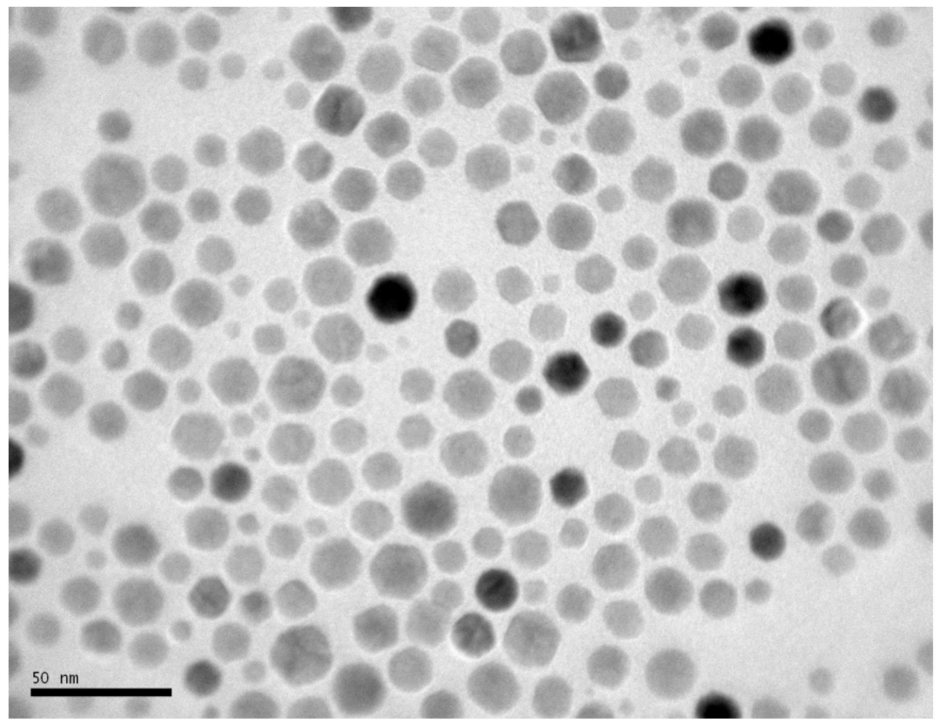

Figure 2. TEM micrograph from the oleate-coated MION colloids.

\section{Results}

Figure 3 shows the AC BDV of both measured nanofluids versus the concentration of nanoparticles as compared with the mean BDV for the natural ester matrix oil which is $64.5 \mathrm{kV}$. 


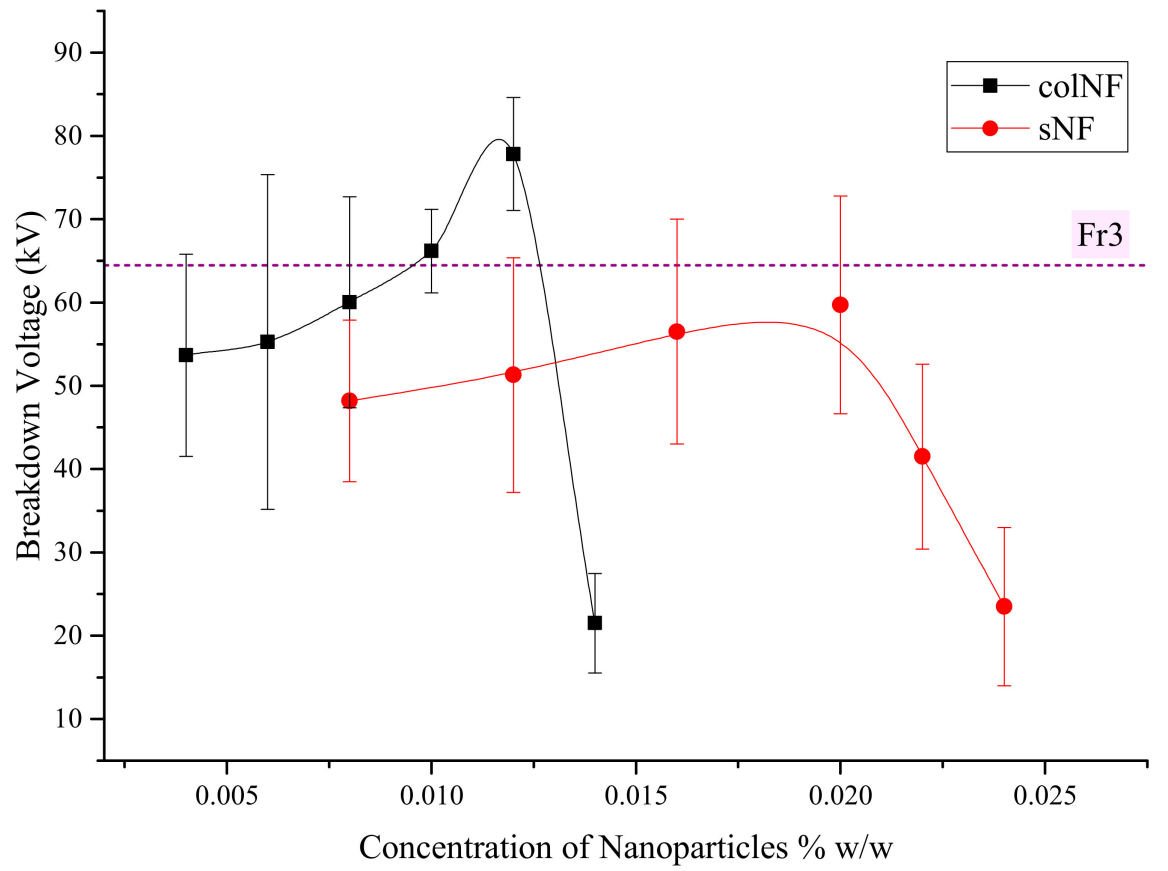

Figure 3. Mean AC breakdown voltage (BDV) versus nanoparticles concentration (colNF and silica NF).

As it is obvious from Figure 3, for the nanofluid with oleate-coated colloidal MIONs (colNF), the BDV increases as the concentration of nanoparticles increases until the $0.012 \% w / w$ concentration, at which point it reaches its maximum value of $77.8 \mathrm{kV}$, while at higher concentrations the BDV decreases sharply. However, colNF exhibits higher BDV than natural ester oil only at $0.008 \% w / w$ and $0.012 \% w / w$ concentrations.

As regards the $\mathrm{BDV}$ of nanofluid with $\mathrm{SiO}_{2}$, nanoparticles (silica NF-sNF) exhibit similar behavior to the colNFs in terms of increasing nanoparticle concentration, although it always remains lower than the BDV of natural ester oil. The maximum BDV value of $59.7 \mathrm{kV}$ is achieved at $0.02 \% w / w$. Any further addition of silica nanoparticles results in an instant drop of the BDV.

Table 1 gives the probabilities $50 \%, 10 \%$, and $1 \%$ for the three dielectric liquids, as well as their standard deviation. In addition, to enable a comparison, in Table 1 the results from two other nanofluids are given, i.e., the probabilities $50 \%$ and $10 \%$ for $\mathrm{TiO}_{2} 0.007 \% w / w$ in ester oil [14] and $\mathrm{SiO}_{2} 0.02 \% w / w$ in mineral oil [19].

Table 1. Breakdown voltage probabilities.

\begin{tabular}{ccccc}
\hline \multirow{2}{*}{ Probability } & \multicolumn{3}{c}{ Breakdown Voltage (kV) } & \multirow{2}{*}{ Standard Deviation (kV) } \\
\cline { 2 - 4 } & $\mathbf{V}_{\mathbf{5 0} \%}$ & $\mathbf{V}_{\mathbf{1 0} \%}$ & $\mathbf{V}_{\mathbf{1} \%}$ & \\
\hline Natural Ester FR3 & 64.5 & 49.7 & 37.6 & 12 \\
colNF 0.012\% & 77.8 & 69.1 & 62.1 & 6 \\
sNF 0.02\% & 59.7 & 42.7 & 21.7 & 13 \\
$\mathrm{TiO}_{2}$ NF 0.007\% [14] & 30 & 22.7 & N/A & N/A \\
$\mathrm{SiO}_{2}$ NF 0.02\% [19] & 68.5 & 41.7 & N/A & N/A \\
\hline
\end{tabular}

According to Table 1, the two nanofluids show differences not only in the mean value of BDV but also in standard deviation. The BDV values of sNF are more scattered at all ranges of concentrations and standard deviation varies from $9.5 \mathrm{kV}$ up to $14.1 \mathrm{kV}$. The standard deviation of colNF is also large for a nanoparticle concentration of $0.008 \%$ or less, but above this value it declines sharply.

As it is known, the low probabilities of breakdown voltage play a pivotal role in designing electrical apparatus such as transformers [9]. The results from Table 1 show that the colNF appeared 
with the highest value of $\mathrm{V}_{1 \%} \mathrm{BDV}$ which is $62.1 \mathrm{kV}$, while for natural ester oil the value is $37.6 \mathrm{kV}$ and for sNF the value is $21.7 \mathrm{kV}$. This can be attributed to its extremely low standard deviation.

The Impact of Nanoparticles on Dielectric Behavior of Insulating Oil

A considerable amount of research has already been carried out to date to explain the enhanced dielectric behavior of nanofluids [12,20-25]. In [20,21], these are attributed to the capability of nanoparticles to trap electrons. This happens due to inductive charging for the conductive nanoparticles and by means of polarization for the non- and semi-conductive nanoparticles.

When an external electric field, $E_{0}$, is applied to the gap, the electrical charges of a conductive nanoparticle are redistributed inversely along the direction of the electric field within a relaxation time, $\tau_{r}$. The relaxation time is expressed as follows [22]:

$$
\tau_{r}=\frac{2 \varepsilon_{1}+\varepsilon_{2}}{2 \sigma_{1}+\sigma_{2}}
$$

where, $\varepsilon_{1}$ and $\varepsilon_{2}$ are the permittivity of transformer oil and nanoparticle, respectively and $\sigma_{1}$ and $\sigma_{2}$ are the conductivities of transformer oil and nanoparticle respectively. Conductive NPs, such as $\mathrm{Fe}_{3} \mathrm{O}_{4}$ or $\mathrm{ZnO}$, have a very small relaxation time of the order of $10^{-11}-10^{-14} \mathrm{~s}$ [20] as can be seen in Table 2. Non-conductive NPs on the other hand have large relaxation times. However, bound charges are formed on their surface due to polarization. Electronic and ionic displacement polarizations are generated very quickly in $10^{-15} \mathrm{~s}$ to $10^{-12} \mathrm{~s}$. It should be noted that conductive NPs with large dielectric permittivity contain both induced and polarized charges on their surface.

Table 2. Relaxation time of indicative nanoparticles adapted from Hwang et al. [20].

\begin{tabular}{cccccc}
\hline Nanoparticles & $\mathrm{Fe}_{3} \mathbf{O}_{\mathbf{4}}$ & $\mathrm{ZnO}$ & $\mathbf{A l}_{\mathbf{2}} \mathbf{O}_{\mathbf{3}}$ & $\mathbf{S i O}_{\mathbf{2}}(\mathbf{Q u a r t z})$ & $\mathbf{S i O}_{\mathbf{2}}($ Silica $)$ \\
\hline Relaxation Time (s) & $7.47 \times 10^{-14}$ & $1.05 \times 10^{-11}$ & 12.2 & 36.3 & $5.12 \times 10^{-2}$ \\
\hline
\end{tabular}

The potential well due to the redistributed charges on the surface of conductive nanoparticles is given for the direction of the applied field $(\theta=0)$ and for the opposite direction $(\theta=\pi)$ by [22]:

$$
\varphi_{c N P}=\left\{\begin{array}{l}
\frac{\sigma_{2}-\sigma_{1}}{2 \sigma_{1}+\sigma_{2}} R^{3} E_{0} \frac{1}{r^{2}}\{\theta=0, r \geq R \\
-\frac{\sigma_{2}-\sigma_{1}}{2 \sigma_{1}+\sigma_{2}} R^{3} E_{0} \frac{1}{r^{2}}\{\theta=\pi, r \geq R
\end{array}\right.
$$

where, $\sigma_{1}$ and $\sigma_{2}$ are the conductivities of transformer oil and nanoparticles respectively, $R$ is the radius of nanoparticle, $E_{0}$ is the applied field, and $r$ the distance from nanoparticles surface.

On the exterior of a non-conductive nanoparticle, the potential well is given by [22]:

$$
\varphi_{n c N P}=\left\{\begin{array}{l}
\frac{\varepsilon_{2}-\varepsilon_{1}}{2 \varepsilon_{1}+\varepsilon_{2}} R^{3} E_{0} \frac{1}{r^{2}}\{\theta=0, r \geq R \\
-\frac{\varepsilon_{2}-\varepsilon_{1}}{2 \varepsilon_{1}+\varepsilon_{2}} R^{3} E_{0} \frac{1}{r^{2}}\{\theta=\pi, r \geq R
\end{array}\right.
$$

where, $\varepsilon_{1}$ and $\varepsilon_{2}$ are the permittivity of transformer oil and nanoparticle respectively. Fast moving electrons are captured by the potential well, forming negatively charged nanoparticles. The latter nanoparticles are introduced with slower mobility and charged negatively, as a consequence the streamer speed is reduced which leads to increased breakdown voltage. Equations (4) and (5) give the total amount of charges trapped by a conductive nanoparticle and non-conductive, respectively [22]:

$$
\begin{gathered}
Q_{c N P}=-12 \pi \varepsilon_{1} E_{0} R^{2} \\
Q_{n c N P}=-12 \pi \varepsilon_{1} E_{0} R^{2} \frac{\varepsilon_{2}}{2 \varepsilon_{1}+\varepsilon_{2}}
\end{gathered}
$$


Table 3 depicts the conductivity and permittivity of the colMIONs, $\mathrm{SiO}_{2}$, and natural ester oil FR3. As mentioned above, the colMIONs were synthesized in situ, thus their conductivity and permittivity are accurately considered equal to that of a commercial $\mathrm{Fe}_{2} \mathrm{O}_{3} \mathrm{NP}$.

Taking into account Equations (3) and (4), as well as the values of Table 3, the potential well of the suspended colMIONs and $\mathrm{SiO}_{2}$ are given as [22]:

$$
\begin{gathered}
\varphi_{\text {colMION }}=1.25 \cdot E_{0} \cdot \frac{1}{r^{2}} \cdot 10^{-25}[\mathrm{~V}] \\
\varphi_{\mathrm{SiO} 2}=1.9 \cdot E_{0} \cdot \frac{1}{r^{2}} \cdot 10^{-26}[\mathrm{~V}]
\end{gathered}
$$

where, $E_{0}$ is the average electric field and $\mathrm{r}$ is the distance from the surface of the nanoparticle.

Table 3. Breakdown voltage probabilities.

\begin{tabular}{cccc}
\hline Dielectric Lquid & Conductivity $\sigma(\mathrm{S} / \mathrm{m})$ & $\begin{array}{c}\text { Relative Permittivity } \varepsilon \\
(\mathrm{F} / \mathbf{m})\end{array}$ & $\begin{array}{c}\text { Average Nanoparticle } \\
\text { Diameter } \boldsymbol{R}(\mathbf{n m})\end{array}$ \\
\hline Natural Ester FR3 & $5 \times 10^{-14}$ & 3.2 & - \\
colMION & $1 \times 10^{4}$ & 80 & 10 \\
$\mathrm{SiO}_{2}$ & $1.4 \times 10^{-11}-1 \times 10^{-15}$ & $3.7-4$ & 12 \\
\hline
\end{tabular}

The electric field, $E_{0}$, for colNF is calculated as $31.12 \times 10^{6} \mathrm{~V} / \mathrm{m}$ and for sNF as $23.88 \times 10^{6} \mathrm{~V} / \mathrm{m}$ considering that the breakdown voltage for colNF and sNF is $77.8 \mathrm{kV}$ and $59.7 \mathrm{kV}$, respectively, for a gap of $2.5 \mathrm{~mm}$. Substituting these values of electric field $E_{0}$, as well as the values of average nanoparticle diameter $R$ from Table 3, into Equations (4) and (5) for the colMIONs and $\mathrm{SiO}_{2} \mathrm{NPs}$, respectively, their saturation charges are:

$$
Q_{\text {colMION }}=-0.83 \times 10^{-18} \mathrm{C} \text { and } Q_{\mathrm{SiO}_{2}}=-0.35 \times 10^{-18} \mathrm{C}
$$

Accordingly, substituting the above electric field values $E_{0}$ into Equations (6) and (7), the potential well as a function of the distance from the nanoparticles' surface before breakdown occurs is given in Figure 4 for both nanoparticles in question.

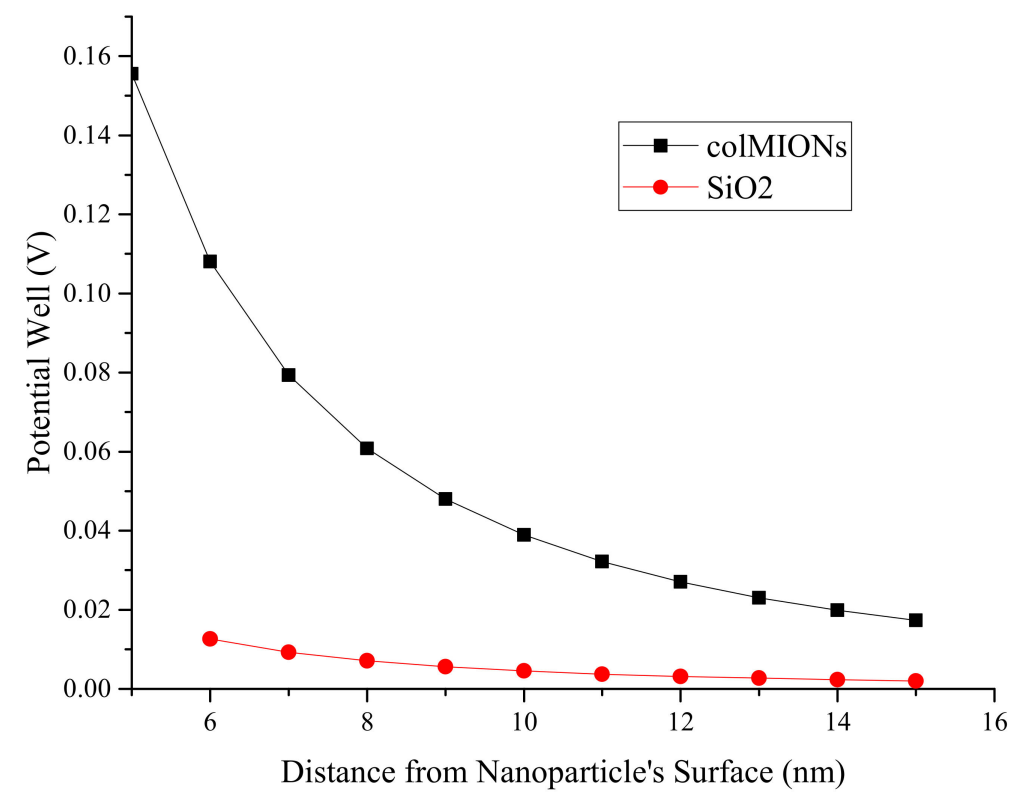

Figure 4. Potential well distribution of oleate-coated colloidal magnetic iron oxide nanocrystals (colMION) and $\mathrm{SiO}_{2}$ nanoparticles versus the distance from the nanoparticle's surface. 
Figure 4 shows the difference in the potential well between colMIONs and sNF and especially near the nanoparticle's surface. The saturation charges of nanoparticles Equation (8) with respect to the potential well of colMIONs (Figure 4), indicate their higher capability to trap electrons generated from ionization or injection in the bulk of dielectric liquid which can affect the streamer early development. The above is an indication of the better dielectric performance of colNF as compared to sNF which is due to the increased potential well of the colNF.

The results from dielectric relaxation spectroscopy study for natural ester oil and colNF $0.012 \%$ $w / w$ at $20^{\circ} \mathrm{C}$ and $100^{\circ} \mathrm{C}$ for a frequency range of $10^{-1}-10^{6} \mathrm{~Hz}$ are given in Figure 5.

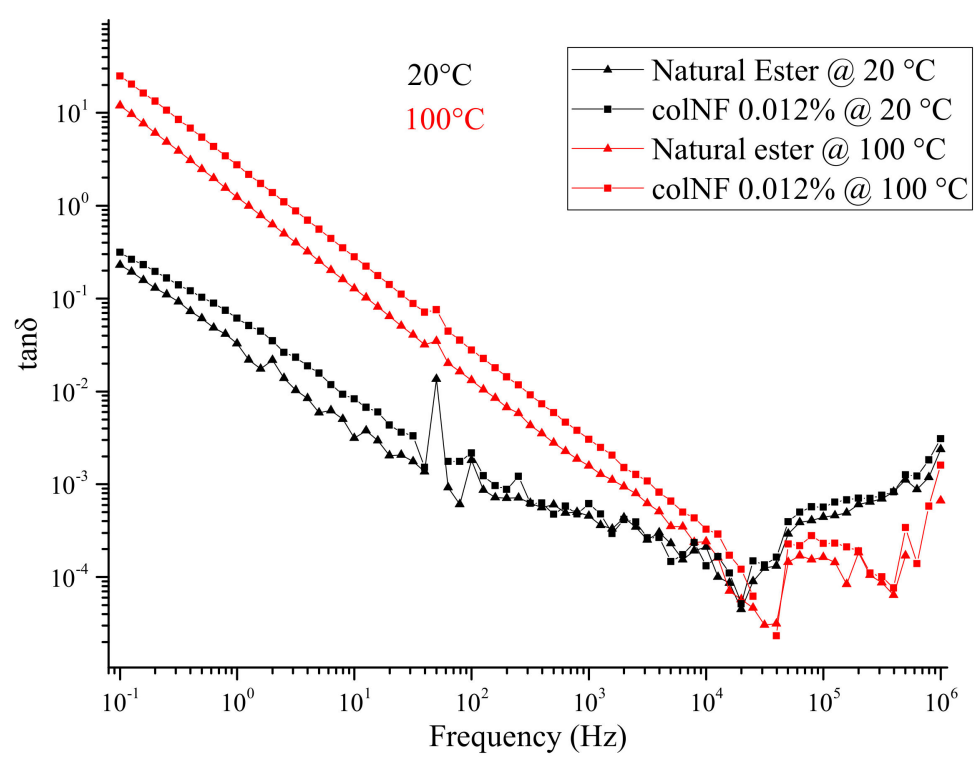

Figure 5. Dielectric losses $(\tan \delta)$ for natural ester oil and colNF $0.012 \%$ at $20^{\circ} \mathrm{C}$ and $100{ }^{\circ} \mathrm{C}$.

From Figure 5 it is demonstrated that the dielectric losses $(\tan \delta)$ are reduced by increasing the frequency and increased by increasing the temperature. A differentiation of the dielectric losses response is monitored at the frequency regime above $20 \mathrm{kHz}$ associated with high frequency relaxations.

\section{Discussion}

It is well known that the presence of conductive and non-conductive solid particles inside insulating oils results in the decrease of breakdown voltage [29-32]. All the relevant studies that have been conducted concern solid particles with sizes of the order of several hundred $\mu \mathrm{m}$. However, the basic theory can be extended to the nm scale. This effect is also observed in Figure 3, for low and high concentrations of both dispersed nanoparticles in the vicinity of the matrix oil.

However, the increase of BDV of nanofluids for specific concentrations of nanoparticles indicates the presence of an opposite physical mechanism which enhances the dielectric properties. This mechanism was explained satisfactorily in $[20,22]$ and the experimental results of this work are in compliance with the proposed theory as analyzed in the previous section. Nanoparticles should have either high conductivity or higher permittivity than that of pure insulating oil, in order to act as electron scavengers and reduce the speed of streamer. The colMIONs succeeded due to their high conductivity while $\mathrm{SiO}_{2}$ failed to improve the dielectric characteristics of insulating oil. This is also valid for $\mathrm{TiO}_{2}$ nanofluid as its probabilities of BDV are much lower than the matrix oil [14], as can be seen in Table 1.

On the other hand, $\mathrm{SiO}_{2}$ nanoparticles in [19] seem to have a better $50 \%$ probability (Table 1 ) just as other studies [15-17] reveal a better performance of silica nanofluids in contrast to the experimental results of this work. However, in all these studies, mineral oil was used as the base for the synthesis of nanofluids. Mineral oil exhibits lower permittivity $\left(e_{r}=2\right)$ as compared to natural ester oil $\left(e_{r}=3.2\right)$ and this fact enhances the ability of silica nanoparticles to capture electrons. Another issue seems to be the 
presence of moisture, since $\mathrm{SiO}_{2}$ nanoparticles can absorb large amounts of moisture. Water absorption demonstrates higher conductivity and relative permittivity than $\mathrm{SiO}_{2}$ and thus it enhances the electron trapping capability of $\mathrm{SiO}_{2}$ nanoparticles.

In this study, nanofluid samples were tested shortly after their preparation, and therefore nanoparticles did not have the time to absorb moisture from the vicinity of the oil.

For lower concentrations than optimum, for both nanofluids tested, BDVs are lower than that of matrix oil but with an upward trend with the increase of nanoparticle concentration. For concentrations above the optimum, BDVs are also lower than that of matrix oil but with a steadily downward trend.

As was aforementioned, both conductive and non-conductive nanoparticles are charged when subjected to an external electric field. As the concentration of nanoparticles increases, they will form thin filaments that oscillate across the gap. When the filaments reach a critical length, a conductive bridge path is formed and a breakdown discharge will be triggered. As long as the enhancement mechanism overcomes the negative impact of solid impurities on transformer oil, BDV versus concentration will exhibit an upward trend. When the concentration of nanoparticles exceeds a critical value, the negative impact of the presence of solid particles dominates, and the BDV of the nanofluid rapidly decreases.

\section{Conclusions}

In this study, the dielectric insulation characteristics for two types of nanofluids based on a natural ester matrix were studied with respect to the influence of electrical conductivity and permittivity of the NPs on the AC dielectric strength of nanofluids. Two types of nanoparticles were studied, oleate-coated colloidal magnetic $\mathrm{Fe}_{2} \mathrm{O}_{3}$ nanocrystals (colMIONs) exhibiting high conductivity and permittivity and $\mathrm{SiO}_{2} \mathrm{NPs}$ exhibiting low conductivity and permittivity.

The experimental results of this study are in compliance with the proposed theories analyzing the impact of NPs on the dielectric strength of transformer oil-based nanofluids. NPs with higher electrical conductivity or permittivity can exhibit improved dielectric performance by adding them in the matrix oil. Particularly the introduction of colNF consisting of conductive colMIONs, demonstrates an improved AC breakdown voltage of $77.8 \mathrm{kV}$ at $0.012 \% w / w$ concentration as compared with $64.5 \mathrm{kV}$ AC BDV for the base matrix oil. Simultaneously, they exhibit improved field operation reliability taking into account that the $\mathrm{U}_{1}$ breakdown voltage was considerably high, equal to $62.1 \mathrm{kV}$, which is remarkably higher than the $U_{1}$ of $37.2 \mathrm{kV}$ of the matrix oil. The aforementioned performance is correlated to the substantially low standard deviation in the range of $6.7 \mathrm{kV}$. Additionally, the dielectric losses of the colNF studied at $25^{\circ} \mathrm{C}$ and $100{ }^{\circ} \mathrm{C}$ in the frequency regime of $10^{-1}-10^{6} \mathrm{~Hz}$ behaved similarly to the matrix oil, that is, they reduced as the frequency increased and increased as the temperature increased, but with slightly higher values than that of matrix oil.

In contrast, the $\mathrm{AC}$ breakdown voltage of silica NF with $\mathrm{SiO}_{2} \mathrm{NPs}$ is reduced as compared to that of the matrix oil for all the ranges of NPs concentrations that were investigated herein. The explanation of the abovementioned dielectric performance is correlated with the low electrical conductivity as well as the permittivity of silica NPs, along with their low capability of capturing free electrons. Furthermore, an in-depth research study is needed which takes into account the electrical conductivity and permittivity in order to discriminate the influence of moisture content on the dielectric strength performance of the nanofluids.

Author Contributions: Conceptualization: V.P.C., G.D.P., E.C.P.; Methodology: G.D.P.; Manufacturing of ColMIONs and characterization: A.B., G.D.P.; Preparation of NFs: A.B., G.D.P.; Measurements of BDV: G.D.P.; Measurements of dielectric losses: G.D.P., A.D.P.; Statistical analysis and Analysis of results: V.P.C., G.D.P., A.D.P.; Theoretical Analysis: V.P.C., G.D.P., A.D.P.; Writing: V.P.C., G.D.P., A.D.P.; Review: V.P.C., G.D.P., E.C.P., A.B., A.D.P., I.F.G.; Supervision: E.C.P., I.F.G.

Funding: This research received no external funding.

Acknowledgments: The authors warmly acknowledge Kevin Rapp Senior scientist of Cargill for the FR3 oil supply during this research.

Conflicts of Interest: The authors declare no conflict of interest. 


\section{References}

1. Maxwell, J.C. A Treatise on Electricity and Magnetism, 2nd ed.; Clarendon Press: Oxford, UK, 1881; Volume 1, p. 435.

2. Choi, S.U.S.; Eastman, J.A. Enhancing Thermal Conductivity of Fluids with Nanoparticles. In Proceedings of the 1995 International Mechanical Engineering Congress Exposition, San Francisco, CA, USA, 12-17 November 1995; pp. 99-105.

3. Chiesa, M.; Sarit, D. Experimental investigation of the dielectric and cooling performance of colloidal suspension in insulating media. Colloids Surf. A Physicochem. Eng. Asp. 2009, 335, 88-97. [CrossRef]

4. Mergos, J.; Athanassopoulou, M.; Argyropoulos, T.; Vassiliou, P.; Dervos, C.T. Dielectric properties of nanopowder dispersions in paraffin oil. IEEE Trans. Dielectr. Electr. Insul. 2012, 19, 1502-1507. [CrossRef]

5. Nazari, M.; Rasoulifard, M.; Hosseini, H. Dielectric breakdown strength of magnetic nanofluid based on insulation oil after impulse test. J. Magn. Magn. Mater. 2016, 339, 1-4. [CrossRef]

6. Du, B.; Li, X.; Li, J. Thermal conductivity and dielectric characteristics of transformer oil filled with BN and $\mathrm{Fe}_{3} \mathrm{O}_{4}$ nanoparticles. IEEE Trans. Dielectr. Electr. Insul. 2015, 22, 2530-2536. [CrossRef]

7. Li, J.; Zhang, Z.; Zou, P.; Grzybowski, S.; Zahn, M. Preparation of vegetable oil based nanofluid and investigation of its breakdown and dielectric properties. IEEE Electr. Insul. Mag. 2012, 28, 43-50. [CrossRef]

8. Cavallini, A.; Negri, F. Behaviour of nanofluids under DC divergent fields. In Proceedings of the IEEE International Conference on Dielectrics, Montpellier, France, 3-7 July 2016. [CrossRef]

9. Peppas, G.D.; Bakandritsos, A.; Charalampakos, V.P.; Tucek, J.; Zboril, R.; Pyrgioti, E.C.; Gonos, I.F. Ultrastable natural ester based nanofluids for high voltage insulation applications. ACS Appl. Mater. Interfaces 2016, 8, 25202-25209. [CrossRef] [PubMed]

10. Peppas, G.D.; Charalampakos, V.P.; Pyrgioti, E.C.; Danikas, M.G.; Bakandritsos, A.; Gonos, I.F. Statistical investigation of AC breakdown voltage of nanofluids compared with mineral and natural ester oil. IET Sci. Meas. Technol. 2016, 10, 644-652. [CrossRef]

11. Taha-Tijerina, J.; Narayanan, T.N.; Gao, G.; Rohde, M.; Tsentalovich, D.A.; Pasquali, M.; Ajayan, P.M. Electrically insulating thermal nano-oils using 2D fillers. ACS Nano 2012, 6, 1214-1220. [CrossRef]

12. Atiya, E.G.; Mansour, D.E.A.; Khattab, R.M.; Azmy, A.M. Dispersion behavior and breakdown strength of transformer oil filled with $\mathrm{TiO}_{2}$ nanoparticles. IEEE Trans. Dielectr. Electr. Insul. 2015, 22, $2463-2472$. [CrossRef]

13. Du, Y.; Lv, Y.; Li, C.; Chen, M.; Zhou, J.; Li, X.; Zhou, Y.; Tu, Y. Effect of electron shallow trap on breakdown performance of transformer oil-based nanofluids. J. Appl. Phys. 2011, 110, 104104-1-4. [CrossRef]

14. Zhong, Y.; Lv, Y.; Li, C.; Du, Y.; Chen, M.; Zhang, S.; Zhou, Y.; Chen, L. Insulating properties and charge characteristics of natural ester fluid modified by $\mathrm{TiO}_{2}$ semiconductive nanoparticles. IEEE Trans. Dielectr. Electr. Insul. 2013, 20, 135-140. [CrossRef]

15. Jin, H.; Andritsch, T.; Tsekmes, I.A.; Kochetov, R.; Morshuis, P.H.F.; Smit, J.J. Properties of Mineral Oil Based Silica Nanofluids. IEEE Trans. Dielectr. Electr. Insul. 2014, 21, 1100-1108. [CrossRef]

16. Rafiq, M.; Li, C.; Lv, Y.; Yi, K.; Arif, I. Breakdown characteristics of transformer oil based silica nanofluids. In Proceedings of the IEEE International Multi Topic Conference (INMIC), Islamabad, Pakistan, 5-6 December 2016; pp. 1-4. [CrossRef]

17. Cavallini, A.; Karthik, R.; Negri, F. The effect of Magnetite, grapheme oxide and silicone oxide nanoparticles on dielectric withstand characteristics of mineral oil. IEEE Trans. Dielectr. Electr. Insul. 2015, 22, 2592-2600. [CrossRef]

18. Liu, D.; Zhou, Y.; Yang, Y.; Zhang, L.; Jin, F. Characterization of high performance AIN nanoparticle-based transformer oil nanofluids. IEEE Trans. Dielectr. Electr. Insul. 2016, 23, 2757-2767. [CrossRef]

19. Lv, Y.Z.; Zhou, Y.; Li, C.R.; Wang, Q.; Qi, B. Recent progress in nanofluids based on transformer oil: Preparation and electrical insulation properties. IEEE Electr. Insul. Mag. 2014, 30, 23-32. [CrossRef]

20. Hwang, G.J.; Zahn, M.; O'Sullivan, F.M.; Pettersson, L.A.A.; Hjortstam, O.; Liu, R. Effects of nanoparticle charging on streamer development in transformer oil-based nanofluids. J. Appl. Phys. 2010, 107, 014310-1-17. [CrossRef]

21. Yang, Q.; Yu, F.; Sima, W.; Zahn, M. Space charge inhibition effect of nano- $\mathrm{Fe}_{3} \mathrm{O}_{4}$ on improvement of impulse breakdown voltage of transformer oil based on improved Kerr optic measurements. AIP Adv. 2015, 5, 097207-1. [CrossRef] 
22. Sima, W.; Shi, J.; Yang, Q.; Huang, S.; Cao, X. Effects of conductivity and permittivity of nanoparticle on transformer oil insulation performance: Experiment and theory. IEEE Trans. Dielectr. Electr. Insul. 2015, 22, 380-390. [CrossRef]

23. Tanaka, T.; Kozako, M.; Fuse, N.; Ohki, Y. Proposal of a multi-core model for polymer nanocomposite dielectrics. IEEE Trans. Dielectr. Electr. Insul. 2005, 12, 669-681. [CrossRef]

24. Izzularab, M.; Ibrahim, M.; Abd-Elhaby, A. Effect on transformer oil breakdown strength: Experiment and theory. IET Sci. Meas. Technol. 2016, 10, 839-845. [CrossRef]

25. Liong, M.; Lu, J.; Kovochich, M.; Xia, T.; Ruehm, S.G.; Nel, A.E.; Tamanoi, F.; Zink, J.I. Multifunctional inorganic nanoparticles for imaging, targeting and drug delivery. ACS Nano 2008, 2, 889-896. [CrossRef]

26. Peppas, G.; Bakandritsos, A.; Pyrgioti, E. Method of Making and Synthesizing Dielectric Nanofluids. Patent WO2018020278A1, 12 July 2017.

27. Peppas, G.D.; Charalampakos, V.P.; Pyrgioti, E.C.; Bakandritsos, A.; Polykrati, A.D.; Gonos, I.F. A study on the Breakdown Characteristics of Natural Ester Based Nanofluids with Magnetic Iron Oxide and $\mathrm{SiO} 2$ Nanoparticles. In Proceedings of the IEEE International Conference on High Voltage Engineering and Application (ICHVE), Athens, Greece, 10-13 September 2018. [CrossRef]

28. IEC 60156:2016. Insulating Liquids_Determination of the Breakdown Voltage at Power Frequency-Test Method; International Electrotechnical Commission: Geneva, Swutzerland, 2016.

29. Chadband, W.G. The electrical breakdown of insulating oil. Power Eng. J. 1992, 6, 61-67. [CrossRef]

30. Chadband, W.G. Electrical breakdown of liquid insulation. In Proceedings of the IEE Colloquium on an Engineering Review of Liquid Insulation, London, UK, 7 January 1997. [CrossRef]

31. Mahmud, S.; Chen, G.; Golosnoy, I.O.; Wilson, G.; Jarman, P. Bridging phenomena in contaminated transformer oil. In Proceedings of the IEEE International Conference on Condition Monitoring and Diagnosis, Bali, Indonesia, 23-27 September 2012. [CrossRef]

32. Wang, X.; Wang, Z.D. Particle effect on breakdown voltage of mineral and ester based transformer oils. In Proceedings of the IEEE 2008 Annual Report Conference on Electrical Insulation Dielectric Phenomena, Quebec, QC, Canada, 26-29 October 2008. [CrossRef] 